\title{
Russian comparison constructions with identical word forms
}

\author{
Elena Vilinbakhova \\ St Petersburg University \\ Universitetskaya Embankment, 11, dep. 184 \\ Saint-Petersburg, 199034, Russia \\ e.vilinbakhova@spbu.ru
}

\begin{abstract}
The study is dedicated to Russian comparison constructions with identical word forms, such as dom kak dom lit. 'a house like a house'. In the previous studies it was argued that the construction conveys the meaning of the correspondence of its referent to the stereotype, i.e. dom kak dom means 'a (stereo)typical house'. However, it is shown that the stereotypical analysis does not account for of their all uses: they are successfully employed even in cases when the referent deviates from the stereotype or when the speaker lacks expertise to evaluate its correspondence to the stereotype. In order to provide an alternative analysis that covers all possible uses, it is suggested that comparison constructions with identical word forms (a) are subjective judgements, and (b) convey the meaning that the speaker considers the referent not worth or demanding any special attention in a positive or negative way. This proposal allows to incorporate stereotypical interpretation as a default inference, which is made by the addressee as a plausible explanation for the speaker's opinion. However, the inference can be cancelled due to the contradicting evidence provided by the interlocutors' common knowledge or contextual cues.
\end{abstract}

Keywords: microsyntax; pragmatics; repetitions; Russian; subjectivity

DOI: $10.28995 / 2075-7182-2021-20-1224-1232$

\section{Сравнительные конструкции с тождественными словоформами в русском языке ${ }^{1}$}

\author{
Вилинбахова Е. Л. \\ Санкт-Петербургский государственный университет \\ Университетская наб., 11, ауд. 184 \\ Санкт-Петербург, 199034, Россия \\ e.vilinbakhovalspbu.ru
}

\begin{abstract}
Аннотация
Доклад посвящен сравнительным конструкциям с тождественными словоформами типа дом как дом. Рассматривается подход, позволяющий объяснить случаи употребления конструкций, которые не поддаются анализу в рамках описаний, представленных в литературе. Демонстрируется, что сравнительные КТС являются субъективными суждениями, и предлагается толкование 'говорящий считает, что референт не дает оснований для повышенного внимания к себе'. Интерпретация из предшествующих работ 'соответствие референта норме, стандарту’ представлена как дефолтная инференция адресата, которая может быть отменена при наличии противоречащих ей фоновых знаний или контекстов.
\end{abstract}

Ключевые слова: микросинтаксис; прагматика; повторы; русский язык; субъективность

\footnotetext{
${ }^{1}$ Исследование выполнено за счет гранта Российского научного фонда (проект № 19-78-10048).
} 


\section{1 Вводные замечания}

В современном русском языке широко распространены конструкции с лексическими повторами, включая тавтологии различных типов, противоречия, т. н. лексические клоны, и другие конструкции с тождественными словоформами (далее - КТС, термин из [Санников 2008]).

(1) а. Друзья есть друзья.

б. Мужик как мужик. [пример из Котта Рамузино 2019: 46]

в. Без детей человек не человек. [пример из Булыгина, Шмелев 1997: 446]

г. Знакома с семьей из папы-мамы-2x детей, тоже милье, на великах-роликах вместе катаются, ну прям семья-семья, образиово-показательная. [пример из Гилярова 2010: 92]

Среди подходов к анализу таких конструкций одним из наиболее распространенных является стереотипический подход, согласно которому говорящий указывает, что референт конструкции соответствует стереотипным представлениям о норме [Апресян 1995; Булыгина, Шмелев 1997; Падучева 2004; Апресян и др. 2010; Гилярова 2010; Вилинбахова 2015; Endresen 2019; Крюкова 2020; Урысон 2020]. В противоречиях, как в (1в), соответствие норме отрицается.

Для сравнительной КТС с именными группами из (1б) мужик как мужик, которая является предметом нашего рассмотрения, стереотипический подход представлен в исследованиях [Шведова 1960; Воейкова 2011; Копотев, Стексова 2016; Котта Рамузино 2019 и др.]. Так Н. Ю. Шведова [1960: 85] отмечает, что конструкция имеет значение «соответствия обычному, приближения к норме: дом как дом»; по наблюдению М.Д. Воейковой [2011: раздел 4.2], происходит указание «на типичного представителя класса»; П. Котта Рамузино [2019: 50] также выделяет значение «соответствующий норме» для существительных, отмечая, что при заполнении слотов глаголами и наречиями значение конструкции меняется.

Указанное значение кажется оправданным для многих случаев употребления конструкции. Например, в (2) после сравнительной КТС эксплицитно перечислены стереотипические признаки кошки, а в (3) подчеркивается соответствие Мальты ожиданиям автора.

(2) Стала она жить-поживать. Кошка как кошка. Мышей ловит, молоко лакает, на печке дремлет. [Е. Л. Шварц. Рассеянный волшебник (1940-1950)]

(3) Сейчас проезжаем остров Мальту. Мальта как Мальта - такою ей и быть полагается. Коротенькая. Всю видать. [К. И. Чуковский. Дневник (1904)]

Тем не менее, есть ряд случаев, которые не поддаются предложенному анализу. Во-первых, это употребления конструкции при несоответствии референта стереотипу, см. (4), где разноцветное лицо героини не является нормой и не соответствует обычному, традиционному представлению о том, как выглядит среднее лицо.

(4) К ее синяку мы уже попривыкли, так что стало казаться, будто фингал не так уж ее и уродует. Лицо как лицо. Разноцветное. Даже интереснее, что разноиветное. [Елена Хаецкая. Синие стрекозы Вавилона/ Обретение Энкиду (1997)]

Далее возможны употребления сравнительной КТС, когда говорящий не знаком с соответствующим стереотипом. В (5) говорящий использует конструкцию Гена как Гена, хотя едва знает риэлтора Гену и не может судить о том, насколько поведение Гены в описываемый период соответствует его типичному поведению.

(5) Что вы про него так? Гена как Гена. Не хуже других... Почему я с одним Константином должен?! [Андрей Волос. Недвижимость (2000) // «Новый Мир», 2001]

Чтобы объяснить указанные случаи, в докладе изложен альтернативный анализ конструкции. Вместо трактовки, согласно которой говорящий считает, что референт соответствует общепринятому стереотипу или норме, предлагается толкование 'говорящий считает, что референт не дает оснований для повышенного внимания к себе'. 
В отличие от стереотипического подхода, когда говорящий для адекватного употребления конструкции должен знать существующие в коллективе представления о норме и ориентироваться на них, предлагаемая трактовка налагает на говорящего меньше обязательств. Оценка референта как не требующего внимания в положительном или отрицательном смысле (референт может не вызывать лишних проблем или не заслуживать высокой оценки) может происходить на любых основаниях, что делает сравнительные КТС субъективными суждениями.

Ниже приведены аргументы в пользу данной трактовки. Также показано, что интерпретация ‘соответствие референта норме, стандарту, стереотипу' возникает как инференция у слушателя. С позиции адресата соответствие норме является наиболее вероятным основанием, которое побуждает говорящего считать референта не требующим или не стоящим внимания. Впрочем, эта инференция может быть отменена при наличии противоречащих ей данных.

Исследование проведено на материале Национального корпуса русского языка (далее - НКРЯ). В основном корпусе за период с 1900 по настоящее время были собраны 1066 примеров сравнительных $\mathrm{KTC}^{2}$. Такие примеры, как в (6), не включались в выборку, поскольку манифестациями конструкции не являются.

(6) Струве возражал, что связано и что поэт - как поэт, а не частное лицо, - вероятно, не может быть простым атеистом. [С. Г. Бочаров. Литературная теория Константина Леонтьева (2000)]

Изложение построено следующим образом. В разделе 2 предлагается анализ сравнительных как субъективных суждений. Раздел 3 посвящен обсуждению отрицания исключительности как основного значения конструкции. В разделе 4 представлены итоги исследования.

\section{2 Субъективность}

Первое наблюдение заключается в отнесении сравнительных КТС к т.н. субъективным высказываниям (англ. subjective judgements), «имеющих для говорящего статус субъективной истины» [Дмитровская 2003: 50]. В рамках предложенной М.А. Дмитровской оппозиции между мнением-предположением и мнением-оценкой, они относятся ко второму классу. В отличие от тавтологий, устанавливающих тождество, где для естественного употребления конструкций требуется отсылка к разделяемым собеседниками представлениям о норме, сравнительная КТС допускает выражение личного мнения субъекта оценки.

В литературе субъективные высказывания рассматриваются в связи с оценочными предикатами вроде вкусный, интересный и пр., см. [Апресян 1995; Булыгина, Шмелев 1997; Lasersohn 2005; Зализняк 2006; Падучева 2011; Stephenson 2007; Anand 2009; Umbach 2016; Bylinina 2017; Solt 2018]. Для выявления субъективного компонента их значения авторы предлагают ряд диагностических тестов, как-то: (1) сочетаемость с глаголом to find 'находить', (2) допустимость эксплицитного выражения субъекта оценки в оценочных предложных группах (англ. judge PP); (3) возможность их употребления в ситуации “субъективного разногласия" (англ. faultless disagreement, см. [Kölbel 2004]).

Следует отметить, что тесты (1) и (2) лингвоспецифичны. Они работают на английском материале, но не материале языков, где нет полноценных аналогов глагола to find или оценочных предложных групп. Тест на субъективное разногласие (критерий 3), напротив, не имеет подобных ограничений и применим к более широкому классу языков, в частности, к русскому.

Примером субъективного разногласия является (7), где собеседники спорят, вкусной ли является лакрица, и каждый может быть по-своему прав: кому-то лакрица нравится, а кому-то нет.

(7) А: Лакрица очень вкусная.

Б: Нет, у нее ужасный вкус!

\footnotetext{
${ }^{2}$ В качестве иллюстрации приводится также пример (11) из интернет-источников, но он при количественном анализе не учитывался.
} 
Субъективное разногласие противопоставляется фактическому разногласию, см. (8), при котором прав только один из собеседников: число не может быть четным и нечетным одновременно.

(8) A: 27 - четное число.

Б: Неправда, 27 - нечетное число.

Т.Н. Вардомская отмечает, что поскольку участники в (7) оценивают вкус лакрицы каждый со своей позиции, субъективное разногласие не является разногласием в чистом виде. Субъективное разногласие - это, скорее, отрицание того, что с оценкой А согласны оба собеседника. В (8), напротив, речь идет именно об указании на несоответствие фактам, см. [Vardomskaya 2018: 6 и след.]. Таким образом, допустимые в контексте субъективного разногласия выражения выражают мнение говорящего, статус которого может быть, а может и не быть, повышен до общей позиции собеседников.

Сравнительные КТС демонстрируют возможность употребления в контекстах субъективного разногласия. Так, во фрагменте из рассказа Д. Рубиной «Супчик» (9) происходит расхождение во мнениях по поводу детства матери автора. С этого субъективного разногласия начинается повествование о детстве матери в довоенное и военное время, где описаны трудности и лишения, с которыми она столкнулась. Отношение матери к своему детству как к норме основано на ее личном опыте и взаимодействии с такими же осиротевшими, голодными подругами из детского дома. В то же время весь рассказ опровергает ее слова детство как детство, но уже с позиции людей, которые выросли в мирное время, включая самого автора, т.е. разница в оценках вызвана личным опытом, не совпадающим у разных поколений.

(9) Я пытаюсь ее отвлечь и по твоему совету расспрашиваю, расспрашиваю - обо всем. О детстве ее, например. Она говорит: а что? детство как детство, как у всех было... Но мне так не кажется. [Дина Рубина. Медная шкатулка (2011-2015)]

В качестве источника субъективности, кроме зависимости от опыта конкретного субъекта, также выступает многомерность измерений (англ. multidimensionality), по которым может производиться оценка, см. [Solt 2018]. Если для решения о том, можно ли описать конкретную зарплату конструкцией зарплата как зарплата, используется одно измерение - ее размер, то в отношении других сущностей оценка может идти по целому ряду параметров, значимость которых относительно друг друга может различаться. Так, в (10) герой Куприян использует конструкцию для описания окружающей действительности, а его жена Фенечка не соглашается с такой оценкой. Поскольку оба героя выросли в одной климатической зоне, их личный опыт не предполагает значимых различий в оценке, в отличие от (9). С другой стороны, Фенечка обращает внимание на те свойства, которые кажутся Куприяну не стоящими внимания: душистый воздух, пение птиц, цветочные запахи, что и ведет к субъективному разногласию.

(10) - Вечер-то какой, Господи, - вдруг задумчиво восклицает Фенечка.

- Вечер как вечер, самый обыкновенный вечер, ничего я в этом вечере особенного не вижу,

- ворчит Куприян, чуть повертываясь к жене.

— Как ничего особенного? — опять восклицает Фенечка. — А воздух? А заря? А сквориы? И... и вообще все!

- Что же, скворцы как скворцы, — ворчит Куприян, — а воздух как воздух...

Фенечка пожимает плечами.

- Ничего-то вы не понимаете! Эх, эх! Или разучились понимать! [А. Н. Будищев. Вешние зовы // журнал «Пробуждение», 1912, № 24, 1912]

Субъективное разногласие относительно адекватности использования конструкции для наименования референта может быть выражено эксплицитно, как в реплике автора мне так не 
кажется на КТС детство как детство в (9), или имплицитно, как в реплике Фенечки Как ничего особенного? на КТС вечер как вечер в (10)

\begin{tabular}{lcc}
\hline Субъективное разногласие & Количество примеров & Относительная частотность \\
\hline $\begin{array}{l}\text { Эксплицитно выраженное } \\
\text { субъективное разногласие }\end{array}$ & 34 & $26,6 \%$ \\
$\begin{array}{l}\text { Имплицитно выраженное } \\
\text { субъективное разногласие }\end{array}$ & 94 & $73,4 \%$ \\
\hline Всего & $\mathbf{1 2 8}$ & $\mathbf{1 0 0} \%$ \\
\hline
\end{tabular}

Таблица 1. СТ в контекстах субъективного разногласия в основном корпусе НКРЯ (с 1900 г.) ${ }^{4}$

Таким образом, согласно диагностическому тексту на возможность употребления выражения в контекстах субъективного разногласия, КТС входит в класс субъективных суждений. КТС передает субъективную оценку референта говорящим, и ее совпадение с общепринятым стереотипическим представлением возможно, но не обязательно. Это решение позволяет объяснить употребление конструкции в более широком наборе контекстов по сравнению с анализом в предшествующих работах.

\section{3 Отсутствие оснований для повышенного внимания к референту}

Следующий класс примеров, которые не поддаются объяснению в рамках стереотипического подхода, включает употребления при отсутствии достаточной для оценки референта компетенции у говорящего как в (5) выше, (11) или (12). В (11) говорящий видит победительницу конкурса красоты на фотографии впервые и не может оценить, насколько облик девушки на этой фотографии соответствует тому, как она обычно выглядит.

(11) Ну по-хорочему да, Ира, конечно, не топ-модель, но вполне себе среднестатистическая дева средней полосы РФ _..> ничего особенного ведь, Ира как Ира (https://pikabu.ru/story/moskva_24_shutit_navernoe_2506551)

В (12) в общепринятый стереотип жены не входят признаки «молодость» и «красота» (жена может быть любого возраста и обладать любой наружностью). Также сомнительна отсылка к стереотипу определенной социальной группы, в которой 'нормальная жена является / должна быть молодой и красивой’, поскольку говорящий - подросток из бедной семьи - не идентифицирует себя с такой социальной группой.

(12) Стоят на берегу моря, загорелье, белобрысые. А жена... Ну, жена как жена. Красивая. Молодая. [Дина Сабитова. Где нет зимы (2011)]

\footnotetext{
${ }^{3}$ По справедливому наблюдению рецензента, следует отметить, что употребление в контекстах субъективного разногласия возможно и для прочих сравнительных конструкций типа «Вася как Петя». Их естественность в данных контекстах определяется признаком, по которому проводится сравнение в конкретной коммуникативной ситуации. В случае, если признак поддается точному измерению (рост, вес и т.п.), разногласие будет фактическим ([Обсуждения роста Васи] А: Вася как Петя. Б: Неправда, Петя выше на два сантиметра - > А ошибается); оценочный признак допускает субъективное разногласие.

Важно, что в случае с рассматриваемой КТС ее субъективность не зависит от признака сравнения, поскольку выражает позицию говорящего. Даже если эта позиция отличается от общепринятой (А: Петя получает миллион долларов! Б: Зарплата как зарплата), она допустима при определенных обстоятельствах, см. пример (i) из [Pearson 2013: 28] и далее комментарий: «Интуитивно пример является ложным. Если меня спросят, насколько это верно, я вряд ли отвечу, что все зависит от субъекта оценки, как было бы, если бы меня спросили, вкусный ли шпинат. С другой стороны, есть люди, для которых это утверждение справедливо. Если Джон произнесет эту фразу, и я буду знать, что он говорит искренне, мне придется признать, что он сказал правду» (перевод мой - Е.В.).

(i) Soapy dishwater is tasty.

'Мыльная вода вкусная'

4 Данные в таблицах (1-3) получены в результате разметки всех найденных примеров двумя аннотаторами. Были составлены инструкции, которые позволяли выбрать одно из значений параметра. Примеры, которые вызывали разногласия, обсуждались дополнительно.
} 
Предлагаемое объяснение состоит в том, что конструкция указывает не на соответствие референта стереотипическим представлениям о категории, а на отсутствие оснований для повышенного внимания к нему, по мнению говорящего. Передача данного значения налагает на говорящего меньше коммуникативных обязательств, чем указание на соответствие референта норме. Говорящий может считать референта не заслуживающим или не требующим внимания на любом основании без обращения к представлениям об общепризнанном или личном стандарте, что позволяет использовать конструкцию в контекстах, когда говорящий встречает референта впервые в жизни.

Данное значение эксплицитно выражено в (13), где редактор предлагает главному герою заменить заглавие именно потому, что использование конструкции не привлечет читателя.

(13) Он недовольно разгладил лопатинскую рукопись и, прочтя заголовок «Ночь как ночь», поморщился. - Ночь как ночь, день как день! Все тянет заранее объяснить, что ничего особенного не произойдет. Раз ночь как ночь - чего ж тут читать? Или сам перемени, или пусть тебе Гурский за двадиать копеек придумает. [Константин Симонов. Так называемая личная жизнь/ Мы не увидимся с тобой... (1978)]

Употребление конструкций в контекстах с выражениями ничего особенного, ничего странного, ничего необычного и др., где отрицается особый статус референта или наличие у него конкретных значимых качеств, является косвенным подтверждением предлагаемого толкования. Отрицание может быть выражено эксплицитно, см. (13), или имплицитно, как в (14), где вопрос что там интересного является риторическим и передает значение 'ничего интересного', см. табл. 2.

(14) Ну что там интересного? Босяк как босяк. Всегда они были, долго еще будут... Пьянствуют, лентяйничают, и ничего больше. Выдумали тоже моду -- босяки, -- не без раздражения сказал Толстой... [Е. А. Соловьев. В Ясной Поляне (1903)]

\begin{tabular}{lcc}
\hline Отрицание & Количество примеров & Относительная частотность \\
\hline Эксплицитно выраженное отрицание & 157 & $64,6 \%$ \\
Имплицитно выраженное отрицание & 86 & $35,4 \%$ \\
\hline Всего & $\mathbf{2 4 3}$ & $\mathbf{1 0 0} \%$ \\
\hline
\end{tabular}

Таблица 2. Сравнительные КТС в контекстах, отрицающих исключительность референта, в основном корпусе НКРЯ (с 1900 г.)

Еще одно свидетельство в пользу значения отсутствия исключительности у СТ - ее употребление в контекстах, где один из элементов представлен как требующий или стоящий внимания и противопоставлен другому элементу, который проблемы или интереса не представляет, см. таблицу 3. Контраст может иметь место либо (а) между референтом СТ и другими сущностями, либо (б) между разными свойствами одного и того же референта СТ, либо (в) между разными способами субъективной оценки референта СТ.

Первый тип представлен в (15), где мать сравнивает своего сына Максима с другими детьми, не вызывающими проблем и не требующими дополнительного внимания, что и выражено конструкцией. В данном случае отсутствие оснований для повышенного внимания к референту (детям других родителей) оценивается говорящим положительно.

(15) - Это же не деньги, - торопливо сказал Максим. - Это так... Я вытащчить не успел.

И он поскорее начал вынимать из карманов то, что звякало: две гайки, связанные веревочкой, жёлтый латунный ключ, фотокассету без крышки, старинный пятак и сломанную запонку.

- У всех дети как дети, а у меня Плюшкин, - печально сообщила мама. [Владислав Крапивин. Болтик (1976)] 
Примером второго типа является (16), когда камера сверхсилы внешне ничем не примечательна, но может сделать из человека сверсилача.

(16) Что такое камера сверхсиль? С виду бочка как бочка, внутри же - проводка по точной схеме. Вбиваются в доски гвозди, и виток за витком оплетается бочка внутри электропроводом. Дальше включается вилка в сеть, и человек влезает в камеру, которая усиливает биотоки примерно в сто раз.

A вылезает - сверхсилачом! [Евгений Велтистов. Победитель невозможного (1975)]

К третьему типу, во-первых, относятся все примеры субъективного разногласия, см. (11-12) выше и (17), где разные участники коммуникации по-разному оценивают референта СТ - как стоящего или не стоящего внимания. Во-вторых, это случаи как в (18), когда говорящий оценивает референта конструкции по-разному в разные периоды времени.

(17) - Каля, ты посмотри, какое небо! - восторженно сказал он. - Небо как небо... - пожала плечами Каля. - Да нет, оно сегодня какое-то необыкновенное. А какое солнце! [Евгений Евтушенко. Ягодные места (1982)]

(18) И ребята ей очень понравились, это только сначала ей показалось, что ребята как ребята, ничего особенного. [Л. Р. Кабо. Повесть о Борисе Беклешове (1962)]

\begin{tabular}{lcc}
\hline \multicolumn{1}{c}{ Сопоставляемые элементы } & Количество примеров & Относительная частотность \\
\hline Разные сущности & 101 & $24,6 \%$ \\
Разные свойства одной сущности & 145 & $35,3 \%$ \\
Разные оценки одной сущности & 165 & $40,1 \%$ \\
\hline Всего & $\mathbf{4 1 1}$ & $\mathbf{1 0 0} \%$ \\
\hline
\end{tabular}

Таблица 3. Сравнительные КТС в контрастивных контекстах в основном корпусе НКРЯ (с 1900 г.)

Наконец, предлагаемая трактовка позволяет учесть интерпретацию предшественников ('говорящий считает, что референт конструкции соответствует стереотипу или норме'), просто изменив ее статус. Соответствие норме может быть представлено как дефолтная инференция адресата - умозаключение, возникающее как наиболее вероятное обоснование того, почему референт не требует или не достоин внимания с точки зрения говорящего. Такое обоснование возникает в силу универсальных прагматических принципов, см. [Levinson 2000]: если объект или ситуация преподносится говорящим как не требующая внимания (англ. unmarked), то слушающему следует считать ее соответствующей стереотипу и применять к ней привычный алгоритм действий. Если же в общих фоновых знаниях участников общения или в контексте содержится информация, блокирующая данную инференцию (референт явно не соответствует норме или говорящий не может об этом судить), то адресат вынужден искать другое объяснение высказываемой позиции говорящего, включая, например, его личный опыт или настроение, см. рис. 1. 


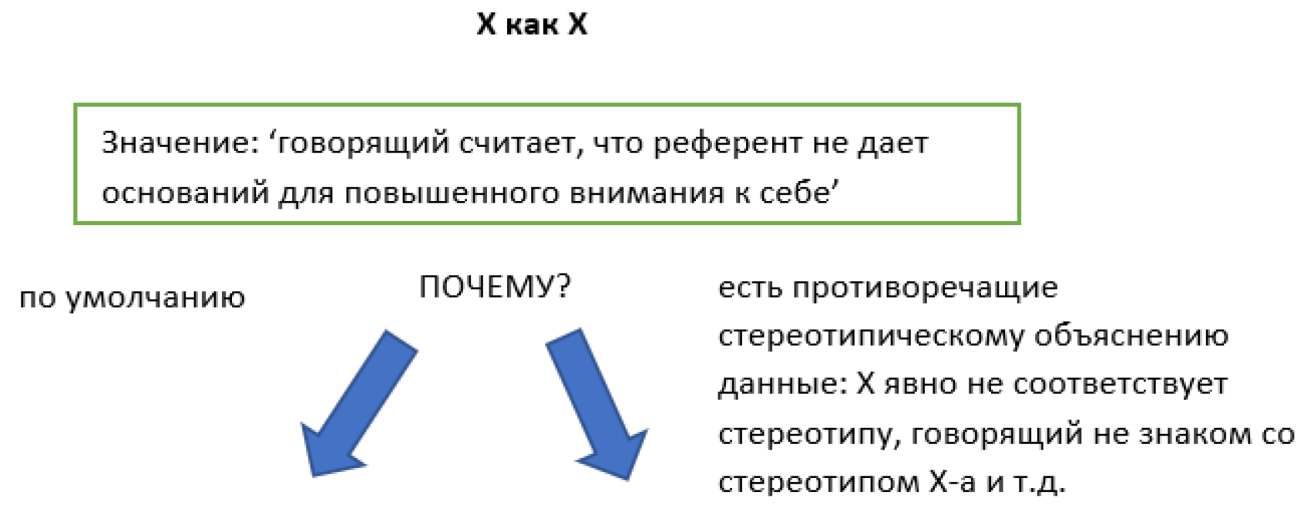

Дефолтная инференция адресата:

'Х соответствует стереотипу'

Запасная инференция адресата: 'У говорящего

есть другие причины считать X-а не требующим

повышенного внимания'

Рис. 1. Интерпретация конструкции $X$ как $X$

\section{4 Заключение}

В докладе были рассмотрены сравнительные конструкции с тождественными словоформами типа люди как люди. Был предложен подход к их интерпретации, позволяющий объяснить случаи употребления, которые не поддаются анализу в рамках представленного в литературе стереотипического подхода. Было показано, что сравнительные КТС являются субъективными суждениями и предложено толкование 'говорящий считает, что референт не дает оснований для повышенного внимания к себе'. Интерпретация 'соответствие референта норме, стандарту' представлена как дефолтная инференция адресата, которая может быть отменена при наличии противоречащих ей фоновых знаний или контекстов.

\section{Благодарности}

Предыдущие версии работы обсуждались на 2-ом Воркшопе ВШЭ по семантике и прагматике (4-5 сентября 2018, совместно с А. В. Крюковой), Лингвистическом семинаре в Национальном университете дистанционного образования (28 ноября 2018), 16-ой Международной прагматической конференции IPRA2019 (9-16 июня 2019), конференциях «Русский язык: конструкционные и лексико-семантические подходы» (3-5 октября 2019, совместно с М. В. Копотевым) и «Интерпретационный потенциал языковой системы и творческая активность говорящего. Языковая личность: варианты речевого поведения〉 (к 85-летию со дня рождения Юрия Николаевича Караулова) (22-24 октября 2020, совместно с М. В. Копотевым). Выражаю благодарность соавторам, участникам и слушателям конференций за плодотворное обсуждение темы. Благодарю Д. Б. Тискина за помощь со сбором и аннотацией материала, а также И. М. Богуславского, Е. В. Маркасову, М. В. Эскандель-Видаль, А. Ю. Шурпицкую и трех анонимных рецензентов за их комментарии и предложения по доработке статьи.

\section{Литература}

[1] Anand P. Kinds of Taste, manuscript. —Santa Cruz : UCSC, 2009.

[2] Bylinina L. Judge-Dependence in Degree Constructions // Journal of Semantics. — 2017. — Vol. 34 (2). P. 291-331.

[3] Endresen A. Well, work and work [Ну работа и работа]: Russian constructions with reduplication. - Talk at November Seminar 2019 in Russian and Russian Studies. —Tromsø, 2019.

[4] Kölbel M. Faultless Disagreement // Proceedings of the Aristotelian Society 2004. — Oxford : Oxford University Press - P. 53-73. 
[5] Lasersohn P. Context Dependence, Disagreement, and Predicates of Personal Taste // Linguistics and Philosophy. - 2005. - Vol. 28 (6). - P. 643-686.

[6] Levinson S. C. Presumptive Meanings: The Theory of Generalized Conversational Implicature. - Cambridge : MIT press, 2000.

[7] Solt S. Multidimensionality, Subjectivity and Scales: Experimental Evidence // The Semantics of Gradability, Vagueness, and Scale Structure. —Cham : Springer, 2018. - P. 59-91.

[8] Stephenson T. Judge Dependence, Epistemic Modals, and Predicates of Personal Taste // Linguistics and Philosophy. — 2007.-Vol. 30 (4). - P. 487-525.

[9] Umbach C. Evaluative Propositions and Subjective Judgments // Subjective Meaning Alternatives to Relativism. - Berlin : De Gruyter, 2016. - P. 127-168.

[10] Vardomskaya T. N. Sources of Subjectivity, manuscript. - Chicago : University of Chicago, 2018.

[11] Апресян Ю. Д. Коннотации как часть прагматики слова // Избранные труды. Т. 2. Интегральное описание языка и системная лексикография. - Москва : Школа «Языки русской культуры», 1995. C. 281-304.

[12] Апресян Ю. Д., Богуславский И. М., Иомдин Л. Л., Санников В. З. Теоретические проблемы русского синтаксиса: Взаимодействие грамматики и словаря. - Москва : «Языки славянских культур», 2010.

[13] Булыгина Т. В., Шмелёв А. Д. Языковая концептуализация мира (на материале русской грамматики). — Москва : Школа «Языки русской культуры», 1997.

[14] Вилинбахова Е. Л. Статья значит статья: об одном классе тавтологических конструкций в русском языке, Компьютерная лингвистика и интеллектуальные технологии: Труды международной конференции «Диалог 2015», - Вып. 14, - Москва, РГГУ, 2015. - С. 638-649.

[15] Воейкова М. Д. Тавтологические двусоставные конструкции // Материалы для проекта корпусного описания русской грамматики (http://rusgram.ru). — Москва, 2011.

[16] Гилярова К. А. Такая девочка-девочка. Семантика редупликации существительных в русской разговорной речи и языке интернета // Компьютерная лингвистика и интеллектуальные технологии: Труды международной конференции «Диалог 2010». - Т. 9. Вып. 16. — Москва : РГГУ, 2010. — С. 90-96.

[17] Дмитровская М. А. Знание и мнение: образ мира, образ человека // Логический анализ языка. Избранное. 1988-1995. — Москва : Индрик, 2003.

[18] Зализняк А. А. Многозначность в языке и способы ее представления. — Москва: «Языки славянских культур», 2006.

[19] Копотев М. В., Стексова Т. И. Исключение как правило: переходные единицы в грамматике и словаре. - Москва : «Языки славянских культур», 2016.

[20] Крюкова А. В. Конструкции с лексическими повторами и общие фоновые знания: разновидности и ограничения // Компьютерная лингвистика и интеллектуальные технологии: По материалам ежегодной международной конференции «Диалог». — Вып. 19 (26). Дополнительный том. — Москва : РГГУ, 2020. - C. $1025-1035$.

[21] Котта Рамузино П. Мужик как мужик: Об одной сравнительно-тавтологической конструкции в русском языке // Scando-Slavica. — 2019. - Vol. 65-1. - P. 42-61.

[22] Национальный корпус русского языка. — 2003-2021. - Доступно по адресу: www.ruscorpora.ru

[23] Падучева Е. В. Динамические модели в семантике лексики. — Москва : Школа «Языки славянской культуры», 2004.

[24] Санников В. 3. Русский синтаксис в семантико-прагматическом пространстве. - Москва : «Языки славянских культур», 2008.

[25] Урысон Е. В. Об одном типе русских предложений тождества (Платье и платье, ничего особенного) // Труды Института русского языка им. В. В. Виноградова РАН. - 2020. - Выпуск 25. От семантических кварков до вселенной в алфавитном порядке. К 90-летию академика Юрия Дерениковича Апресяна. Отв. ред. выпуска Л. Л. Иомдин, И. М. Богуславский. - С. 104-115.

[26] Шведова Н. Ю. Очерки по синтаксису русской разговорной речи. — Москва : Изд-во Академии наук CCCP, 1960. 